\title{
14
}

\section{WEAVING THE GOLDEN NET}

In which Darwin's vision leads us inevitably to the concept of Gaia, a unified, self-organising, self-sustaining, finite, world.

The connectedness of the biosphere is embodied in the concept of Gaia. It was the name suggested by a great writer, William Golding, to personify the insights of James Lovelock. Another great author, this time a woman, AS Byatt (2012), suggested another evocative image.

The surface of the earth was like a great embroidered cloth, or rich tapestry, with an intricately woven underside of connected threads.

Both images emphasise the connections that join living forms and anchor them to the rocky mantle of the Earth and the depths of the oceans. In space they reach the top of the atmosphere and they penetrate deep time, back to the first cell and beyond. It is, above all, a giant integrated whole, a self-maintaining system.

Gaia, in Greek mythology also spelled Gaea, personified Earth. It is not the first time she has been recruited in the name of science. In fact, in another role she has whole disciplines - geology, geography, geometry - named after her. The Gaia of the Greeks was the ancestral mother, the 'broad-bosomed', all-embracing nurturing entity. She is brilliantly evoked by poet Henry Lawson, in his poem On the Night Train, as the 'Mother-Bush', 
Have you seen the bush by moonlight, from the train, go running by?

Blackened log and stump and sapling, ghostly trees all dead and dry; Here a patch of glassy water; there a glimpse of mystic sky?

Have you heard the still voice calling - yet so warm, and yet so cold:

'I'm the Mother-Bush that bore you! Come to me when you are old'?

Margulis's acid 'Gaia is a tough bitch!' was a response to accusations of resurrecting an outdated and fundamentalist concept of a nurturing Mother Nature, the idea illustrated by Lawson's poem. Lawson, however, is singing Gaia's impersonal qualities - 'so warm, and yet so cold'. Indeed, Gaia is tough; and unforgiving. Humanity, alone among organisms, has a choice and it is a stark one. We can be part of Gaia or we can join the 99+ per cent of all those species that ever lived and have now become extinct. In fact, it is no choice at all but a biological imperative. Our longterm future depends on acknowledging that we are part of Gaia, for Gaia is a finite entity and her premature end might be brought about either by our bungling or by cosmic events.

If Gaia's long evolutionary journey is not cut short by an errant asteroid or thoughtless global sterilisation caused by the incessant scientific curiosity and warmongering of the third chimpanzee, she might last another billion years before the expansion of the Sun boils the oceans. Going backwards, halfway into that span of time takes us to the beginning of the Cambrian and its already interesting and complex forms of life. Regressing a further half billion and we are at the start of multicellular organisms. The billion years or so that is left is thus a huge amount time for life to evolve even further. Surely it is worth making the effort to go along for the ride for as long as we can manage it.

Gaia's net is composed of the countless strands of individual genes and sets of genes that extend in time from the first cell to the present day. It includes all the interactions between the genes, chromosomes, all the ecosystems composed of many cooperating species, all the connections with the geosphere and the atmosphere, all the cycles of life, of geological and atmospheric cycles, the chemical cycles of carbon, nitrogen, oxygen and other elements. Gaia is a huge, single entity of interconnected cooperating systems that can maintain itself as long as the Sun shines. The energy from the Sun sustains the whole net; without it, the system disintegrates. Natural selection is the weaver, the process that creates more and more complex patterns as time passes. 


\section{hin \\ male \|l female}

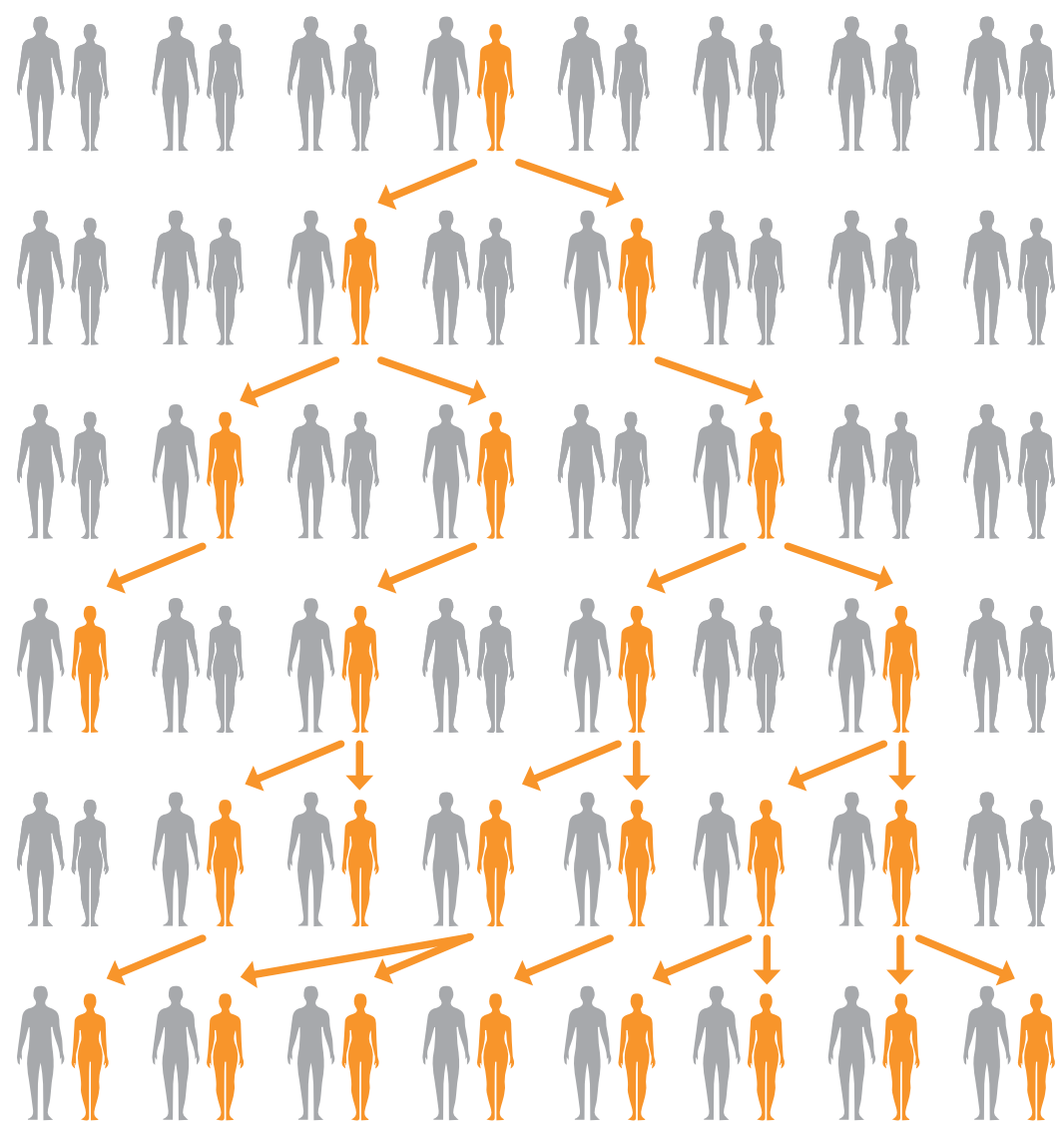

Figure 21. Mitochondrial inheritance.

We can now examine a few of the threads. Inside the cells of humans, animals and plants are found the small, sausage-like organelles that are called mitochondria, what is left of a symbiont. They form a strand in their own right, but they demonstrate some other remarkable properties as they have their own mitochondrial DNA (mDNA) and are able to divide. But there is another important characteristic. 
The mDNA from these ancient modified intracellular symbionts only passes, in humans, through the female line (see Figure 21). Thus, your grandmother received her mDNA from her mother, then passed it to your mother and your mother passed it to you. If you are a woman, your children will also get yours. If you happen to be a man your children will never have yours. Instead they will have that of your partner - which was the mDNA of her mother, and her mother before her and so on. Sadly, sir, from a mitochondrial point of view, you are a dead end! But ... if you have a sister, your maternal mitochondrial line goes on through her children.

In scientific literature, there is a wholly imaginary woman called Mitochondrial Eve, mEve for short. mEve is the ancestress of all living women. The figure shows how her mitochondria might spread through a population. By sampling mDNA from all over the world and identifying the range of variation in mDNA in different populations of people, and assuming a constant mutation rate, geneticists can work out approximately when this most recent ancestress of all living humans was alive (Cann et al. 1987). It is a statistical estimate, based on the rate of mutational change and is always being refined, but the current view is that she lived about 200,000 years ago. This is about the time of the great migrations of modern humans out of Africa.

A generation is usually taken to be 25 years, so mEve lived at least 8,000 generations ago. A similar study of the $\mathrm{Y}$ chromosome in men, not present in women, puts an ancestral yAdam at about the same generational distance (Poznik et al. 2013). Of course, this is only a statistical calculation and does not mean that yAdam and mEve knew each other the odds against that would truly astronomical. And anyway, the couple themselves are imaginary!

There is an 800-year-old story about a fictional Emperor of China who wanted to reward a humble peasant who had done him a great service. Rejecting jewels and land, the peasant said he only needed sustenance and, pointing to a chess board, he asked humbly that one rice grain be placed on the first square, two on the second, four on the third and so on, doubling with each square. The total number of rice grains when the 64 squares have been covered is $18,446,744,073,709,551,615$. This is many times the rice production of the whole world. 
It is also the number of descendants one woman might have after 64 generations - assuming that every one of her descendants did her reproductive duty and had only two offspring, that there was no inbreeding or back-crossing, and that deaths from famine, disease, accident and old age did not occur. When dealing with these progressions, the numbers become eye-wateringly huge very quickly, the observation that provided Malthus with his insight and Darwin with his inspiration. Thus, Genghis Kahn was liberal with his genes and they are now carried by millions. William the Conqueror's genes are likewise to be found, probably, in all native-born English people. Her Majesty the Queen can trace one unbroken line back to William. To perform this trick, you have to know who your ancestors were!

The strands of Gaia's net are made up of the sequential generations of all life but to get a real feel for deep time it is helpful to think in very long human lifetimes, of 100 years. Think about this; when the authors were babies, they could have been cooed over by someone who had been alive in 1837, the year Queen Victoria ascended the throne of England. One more century back, and a newborn might have been inspired by someone who had listened to JS Bach playing his as yet unnamed Brandenburg Concertos at home. A hundred years further back still and King Charles I of England lays his head on the chopping block. Ten such lifetimes from now and people could be watching the Norman Conquest; 20, the Roman invasion of Britain. All of English modern history is therefore embraced by 20 long lifetimes, 80 generations, in evolutionary terms, a very small number.

But other living things are just as remarkable as humans. Ancient cells, such as the intestinal bacterium E. coli, double every 25 minutes or so; its life span is equal to its generation time. You may care to calculate the number of generations this ancient cell has passed through since its earliest ancestor and ponder on the uncountable opportunities provided for natural selection in that time!

At the other end of the scale, a strong contender for the title of the oldest living thing is a species of bristlecone pine tree about 5,000 years of age. The oldest known bristlecone pine alive today was therefore 3,000 years old when the Romans arrived in Britain. It had germinated before the first stone was erected at Stonehenge. Ten thousand years ago the last ice age ended: only two bristlecone pine lifetimes end to end. There were only a few million people worldwide and they were all hunter-gatherers. 
Agriculture in Asia started about 12,000 years ago, and Eridu, the first of the Sumerian cities of Mesopotamia, was established after a further 500 years. Just two bristlecone lifetimes have therefore leapfrogged us past the Egyptian, the Greek and the Mycenaean civilisations, over the Iron and Bronze ages and into the Neolithic. Seven hundred and fifty thousand years before that, or just 150 bristlecone lifetimes end to end, marks the start of the Old Stone Age. Fossil evidence suggests that the earliest known member of the bristlecone pine species lived more than 40 million years ago. At that time, the ancestors of humans were little more than tree shrews, although, being tropical, they never set eyes on a bristlecone pine. That should give you a sense of proportion, if nothing else!

The information contained in our DNA connects us to every person, every other living thing alive. If we take the process far enough back, way beyond the current mEve and yAdam, it connects us with every hominid who ever lived. Back still further the network connects with all animals, plants and fungi until we eventually arrive at that first cell that was formed by a momentous symbiotic event.

Many scientists and science fiction writers have tried to scry their crystal balls for a glimpse of our future. Their stories are often entertaining but, realistically, these are just more 'imagined futures', the creation of which is one of the important functions of the human brain, and one that has played so large a part in our survival. One problem is that these futures are often so far away in time that we have no way of identifying and choosing the most likely one. There is time yet for lots more evolutionary threads to disappear or others to be uncovered by probing life forms of Gaia.

Humans are on the adaptive peak of only one Mount Improbable, to borrow Richard Dawkins's (1996) vivid metaphor, in an adaptive landscape where there are several ranges of improbable mountains, the peaks of which are occupied by different groups of organisms. Setting aside, for the moment, the ubiquity of modern representatives of ancient cells, the peak for absolute population numbers is probably occupied by nematode worms; that for complexity of hive behaviour by the termites, ants and bees; for animal size, by marine organisms (the blue whale at 30 metres, whale shark at 12 metres, the lion's mane jellyfish with a bell of about 3 metres and tentacles extending 40 metres); for longevity, the bristlecone pines; for the largest living organism, a fungus. It is a honey fungus, measuring 3.8 kilometres across, found in the Blue Mountains in 
Oregon. Normally, one would only see the fruiting bodies (mushrooms) but they are connected beneath the ground by a vast network of interlinked branches all carrying the same genome.

And so on. It is possible to say that humans excel in intelligence, collaborative enterprises, in tool making and tool-using to support their continued existence, but at the same time unforeseen outcomes threaten to cut it short. There are others waiting their turn should humanity make a mess of it.

The effects of evolution on humans are best seen in the context of bigger brains. An evolutionary compromise has been reached by the process, discussed elsewhere, of neoteny. This has provided a very successful thread - at least, until now. Brains remain circumscribed by their evolutionary origins. Alfred Sherwood Romer had a view that the brain had evolved in two parts, the 'primitive' and the 'modern'. The primitive brain was the home of existential intelligence, where functions such breathing, reproduction, excretion, intestinal movement and heartbeat, functions that are more than half a billion years old, were controlled without conscious intervention. The modern brain - cerebral hemispheres and associated structures - was where consciousness and behaviour were regulated, so it looked after everything else.

This does not, however, tell us much about the multifunctional capacity of the modern brain. Average men or women are equipped with a set of intelligences, which they can apply, individually or simultaneously, to any problem they encounter. Sadly, most of us have the different intelligences developed to different degrees and must do the best we can.

Studies have shown that infants in orphanages may die without emotional care before they are six years old. If they do not hear a language spoken before they are nine, they will never develop speech. If they do not use their hands (feet can replace them) as they grow, their thinking capacity will be limited. The conclusion is that humans are inherently social animals, co-dependent on opportunities for learning, and needing manual as well intellectual stimulation for growth. They learn to integrate with their social groups and learn of the rewards of cooperative behaviour.

As well as being generalists, humans - and to a lesser, extent bonobos and chimpanzees - are closely cooperative. In a social group all the ways of thinking may not need to be represented in all members but, ideally, the whole spectrum should be employed when addressing an intractable 
problem. There are benefits from working together. Life experiences hone different intelligences in different ways. Individual collective thinking is perhaps possible for gifted polymaths, but collaborative thinking is available within any group of human beings. If cells cooperate, why not minds?

In evolutionary terms, one must assume that animals are equipped with different subsets of intelligences, unknown to us, to enable them to solve the problems posed by their habits of life. They may possess intelligences that humans cannot experience, such as the capacity to perceive and interpret magnetic fields. An eagle, whose visual acuity is essential to its lifestyle, will possess an intelligence consequent on this, while a dog, whose world is largely an olfactory one, will have at least one of its intelligences predicated on an exquisite sense of smell. Humans, being the supreme generalists, are gifted with the wide selection of intelligence and ways of thinking, but blunter sense organs.

Constructing the human contribution to Gaia is a continuing process. At present, in the so-called Anthropocene, we are fixated on the effects of climate change, and especially the human contribution to it by the burning of fossil fuels. We can see extinction happening all around us, our world is changing as we look at it. The ice caps at the poles and in Greenland are melting, the sea is warming, sea levels are rising and weather patterns are changing. We should be ashamed of our part in it. We are at last becoming concerned because our coastal cities, where a large proportion of humanity resides, are threatened. But in spite of all these disruptions, Gaia, this planetary homeostatic mechanism, rolls on, not in the slightest bit concerned, towards a new steady state.

Major evolutionary changes - those changes that end up altering the shapes of animals and plants - are difficult for us to see in our short lifetimes. What we can detect are the myriad small changes that together may have a large effect at some time in the future. And sometimes we can use our new genome technology to look into the past and calculate how long it was since a change to the DNA of a particular population of organisms occurred. A whole meeting of the American Association of Science was devoted to the Biology of Genomes in 2016. Its findings were reported by Elizabeth Pennisi (2016). Here are some more of the results of several of the studies on humans. 
Evolutionary changes can be detected in melanin regulation (skin colour, vitamin D, eye colour). Over the last few thousand years in women, hip size has been increasing, together with head circumference in babies, suggesting that there is continued modification of the neotenic changes that gave rise to modern humans in the first place. Genes for lactose tolerance have also spread rapidly through the British population in the last 2,000 years, presumably reflecting the historical growth of dairy farming. The introduction of milk in the diet had at least one unfortunate repercussion - the spread of tuberculosis (consumption) in Victorian England. In 1924 free milk (now tuberculin tested) in schools was introduced, and so a change of behaviours and increased health followed the first impact of the incorporation of a new component to the human diet; social evolution at its best.

These examples are not, by a long chalk, a summary of all that is happening to the human genome. We belong to an order of which we are the only extant members, yet it is quite clear that we are showing considerable variation, under the impact of our rapidly changing environment. But suppose we consider an order, Coleoptera (beetles), say, with 350,000 described species (or about 22 per cent of all described organisms), or the phylum Nematoda (roundworms), of which 22,000 species have been described, and there may yet be as many 80 million still to go. Now multiply those figures by the number of individuals there are in each species and the brain begins to spin. Yet each one of those individuals is interacting with its changing environment - and, itself, is changing little by little. Evolution is a long-term, widespread continuous process, driven by the process of natural selection and, in humans, social selection.

There has never been a better time to tell this story of an interconnected planet. From an evolutionary point of view, although some of the threads may get broken, change is an opportunity to spin new ones. A vacated peak in the adaptive landscape inevitably becomes occupied by an existing species from elsewhere. If the occupation is successful, its descendants radiate throughout the void, changing gradually as they do so. This is called adaptive radiation and is an important driver of evolution.

It happens every day. As they have little competition, great white sharks seem to be extending their range into the once too-cold waters around the south of Australia. What new opportunities are being extended to their offspring? The bleaching of the Great Barrier Reef provides niches for other plants and animals that may be less attractive to our eyes, but our 
aesthetic sensibilities don't overlap with other species in the overall scheme of life. Plants and animals are advancing up mountains as they become warmer. We do not live long enough to fully perceive these changes and whether we like them is irrelevant. We still have to deal with them.

The environment has moulded humans on their journey to the present. In the last 10,000 years, however, we have gone beyond a passive response to environmental change and have altered and are altering, at an increasing rate, the connections that have helped to create the steady state of Gaia. Notably, this has happened by increasing the return of carbon to the atmosphere in the form carbon dioxide, releasing it from the ancient coal measures at a rate so great that Gaia is unable to sustain the stable atmospheric dynamics that obtained in the middle of the eighteenth century. For those who have eyes to see, this is made manifest by rising global temperatures and atmospheric perturbation in the form of more extreme weather. Gaia is fighting back, quite impersonally, as all homeostatic systems do. We may end up as 'collateral damage'. The more pessimistic students of evolution are suggesting that the effects exerted by humans on the environment have brought us to the end of our line. Others, no less pessimistic suggest that, as humans are innately competitive, they will bring themselves to an end in ever-escalating wars over natural resources, like fresh water and arable land, that might become scarce in Gaia's new steady state.

This book has taken a different view. Throughout, it has argued that the whole evolutionary trajectory is built on cooperation more than competition. The metaphors and other comparisons we have used to emphasise the link between the human condition and the biosphere demonstrate this, we hope, even if some are rather fanciful. And now we are at the point where we have to rely on the major evolutionary attributes of an otherwise generalist species. Humans are quite good at a lot of things but hopelessly outplayed on a one to one comparison; we do not have an eagle's acuity of vision, a dog's olfactory discrimination, a bat's range of hearing, a pigeon's homing instinct, an elephant's strength, a horse's fleetness of foot, a gibbon's gymnastic ability - you can add to this list yourself. What we do have is a larger brain and manipulative hands. We can imagine ourselves doing what other organisms do and so we have made telescopes to enhance out visual acuity; gas chromatographs so that we compete with the olfaction of our pet dog; global positioning systems 
so that we can travel without being able to sense the Earth's magnetic field; cranes, whose strength is far greater than elephants; cars that outrun horses; climbing apparatus that will leave gibbons far behind.

In the previous pages, we have looked at the popular perceptions of 'nature, red in tooth and claw' and 'survival of the fittest' in a different way, one we think that is more consistent with Darwin's own view of life. A literal reading of the first of these applies only to vertebrate carnivores and, given that vertebrates make up a tiny fraction of the less that 1 per cent of biomass of animals on Earth, it is insignificant as a way of life. Invertebrates feed on other invertebrates but this is still only a fraction of this 1 per cent, the rest of whom are herbivores. Yet carnivores have their uses: returning wolves to Yellowstone National Park rejuvenated a tired and depleted ecosystem. Similar observations about the roles of top carnivores have been made elsewhere and now there is a movement to return wolves to Europe. We must consider our own place in this - but it does not mean that we must consent to be eaten!

What would the plants, by far the greatest proportion of the biosphere, make of it all? We would not go so far as to say they consent to being eaten - except those parts such as fruits, seeds and nuts, that are 'designed' to be an attractive food source for animals - and there are plenty of plant adaptations that discourage potential grazers and browsers. They are, however, so constructed that, generally, they survive losing a few leaves and twigs to a marauding giraffe. In so doing they help to nurture the giraffe - and all the inhabitants of its large rumen, not to mention the ultimate benefits of its dung to pasture. Size is just another characteristic of organisms and does not necessarily warrant greater consideration than any other. Looked at in this way, the giraffe, as a dung producer, is simply the first step of a huge matrix of interdependences.

'Survival of the fittest' always conjures up in the popular mind the idea of competition. And that usually means, to the average farmer or gardener, competition between their crop plants and invading weed species. There is a famous cartoon from Punch of a beautiful cottage garden and a plaque on the cottage wall quoting TE Brown's 'A garden is a lovesome thing, God wot'. The proud gardener is leaning on his wall and remarking to an admirer 'You shoulda seen the mess it was in when God had it to hisself?' A well-kept cottage garden (or farm) is so far out of natural equilibrium that it is indeed a battlefield requiring constant supportive assaults from gardener or farmer. 
'Survival of the fittest' might be better rephrased as the 'survival of the luckiest'. Had this been understood in the nineteenth century perhaps a whole lot of human misery might have been avoided, because natural selection really is about luck. And that luck is going for an organism that finds itself in the right place in the wider ecosystem, a place that provides an opportunity for growth and reproduction. As we have seen, it pays sometimes to be a hyper-specialist, like insects with a very specific food range, such as the cabbage white butterfly on brassicas. The butterflies do well as long as some disease does not wipe out cabbages and their kin. For humans, concentrating on a single staple food is likewise dangerous, as those caught up in the tragedy of the Irish famine in the nineteenth century found. That was a special case engineered by cynical politicians. We are generalists; we, like pigs, can eat almost anything, including each other. Normally, if something wipes out potatoes or acorns, we just move on to something else.

As the environment constantly changes it is the task of every living thing to track those changes and adapt to them. Some are always going to be luckier than others that find their favoured environment has become too hot, too cold, too wet, too dry, too crowded, exhausted of nutrients and so on. Nothing is lucky all the time; extinction is commonplace. Something will push the hopeful evolver over the brink, even if it takes worldwide volcanic activity or an asteroid. We are here, and our lineage, from the first sign of life, is exactly as long as every other living thing. We all have a 4-billion-year history of successful adaptation. Together we form the biosphere, the network of biological creation that is the engine of Gaia. We also form our own human net, that Teilhard de Chardin called the noosphere and C Wright Mills 'the sociological imagination'. It is our physical link with the past and fuels our creative capacity for our future. We have enhanced it with a communications technology that we are still learning to control. What a marvellous past it has been and what a marvellous future we may yet have. Sir Charles Sherrington, a neurobiologist who was awarded the Nobel Prize in 1932 would certainly agree. In 1951 he wrote that his book, Man on his Nature,

stresses the view that man [sic] is a product, like so much else, of the play of natural forces acting on the material and under the conditions past and present obtaining on the surface of our planet ... from the side [of the planet] arising shape after shape past fancy. And latterly among them some imbued with sense and thought ... now yielding thoughts and values. 
Recently, a paper entitled 'Gaia 2.0', by Lenton and Latour (2018), put forward a plausible mechanism by which Gaia herself might evolve. It is derived from observations on automata that reset, or 'reboot' themselves. Each time they reboot, they tend to move to a condition of greater stability. Gaia has suffered half a dozen 'great' extinctions - or reboots - and 20-odd 'lesser' extinctions, in each case leading to a new period of stability during which complexity appears to have increased. Thus, each reboot is a resetting, as long as it is not a total extinction event, and Gaia can build on what has gone before. The evolutionary tendency is thus towards stability. Based on this, the so-called Anthropocene is merely a harbinger of a new steady state.

Ancient cells have always had a role and have always been with us in one form or another, inside and out. The first great extinction was brought about as a consequence of one group of ancient cells discovering photosynthesis and poisoning the Earth with oxygen. The response was the emergence of the modern cell that combined the activities of several ancient cells. Ancient cells, the ones that did not enter into such arrangements, persist in astronomical numbers to this day. They join with plants, animals and fungi to contribute to the integrity of Gaia. They, in the form of humanity, have created intelligence. Gaia, Darwin's 'tangled bank' writ large, is thus a testament to the ultimate triumph of ancient cells whose origins go back almost to the origin of the Earth.

Since that time, there have been many steady states of Gaia, all of them capable of supporting life in one form or another. Sometimes the shift to a new steady state has been gradual, sometimes it has been as a result of catastrophe. Until the Industrial Revolution, the steady state shifted imperceptibly. Now we can perceive it happening and, what's more, understand our own less than glorious - perhaps even catastrophic contribution. If humans are an integral part of Gaia, it is reasonable to assume that human consciousness, an essential attribute of humanity, has a role to play in establishing the new steady state.

If we don't play our part, we are just another catastrophe. 
This text is taken from Cooperative Evolution: Reclaiming Darwin's Vision, by Christopher Bryant and Valerie A. Brown, published 2021 by ANU Press, The Australian National University, Canberra, Australia.

doi.org/10.22459/CE.2021.14 